\title{
Repair of unilateral combined orbital floor and medial wall fracture using two titanium mesh plates: a modified technique
}

\author{
Jinguo Yu ${ }^{1}$, Jingkai Zhang ${ }^{1}$, Song Chen $^{1}$, Qi Han ${ }^{1}$, Hua $\operatorname{Yan}^{1,2 \wedge}$ \\ ${ }^{1}$ Department of Ophthalmology, Tianjin Medical University General Hospital, Tianjin, China; ${ }^{2}$ Tianjin Neurological Institute, Key Laboratory of \\ Post-Neuroinjury, Neuro-repair, and Regeneration in Central Nervous System, Ministry of Education and Tianjin City, Tianjin, China \\ Contributions: (I) Conception and design: All authors; (II) Administrative support: All authors; (III) Provision of study materials or patients: All \\ authors; (IV) Collection and assembly of data: All authors; (V) Data analysis and interpretation: All authors; (VI) Manuscript writing: All authors; (VII) \\ Final approval of manuscript: All authors. \\ Correspondence to: Dr. Hua Yan. Tianjin Medical University General Hospital, No. 154, Anshan Road, Tianjin 300052, China.
}

Email: phuayan2000@163.com.

Background: Compared to isolated orbital wall fracture, combined orbital floor and medial wall fractures are more likely to be required surgical correction due to a higher possibility of complications. However, it remains a challenge to repair concomitant orbital fracture using a one-piece implant due to the complex anatomic structures of the orbit. Aiming to reduce surgical difficulties and enhance therapeutic effects, we repaired unilateral combined orbital floor and medial wall fractures using two separated modified titanium mesh plates in this study.

Methods: A retrospective study was conducted on 21 consecutive patients who presented with unilateral combined orbital floor and medial wall fractures in Tianjin Medical University General Hospital between November 2010 and January 2016. The orbital fractures were repaired with two separated titanium mesh plates. The corner at the transition zone area between the orbital floor and the medial wall was reconstructed simultaneously through a combined transcaruncular and inferior subciliary approach with lateral canthotomy. The pre- and post-operative functions and aesthetic results were evaluated.

Results: Preoperatively, all patients presented with 3.5-6.5 mm enophthalmos, five patients presented with diplopia with ocular motility limitation in injured eyes, and six patients presented with hypoglobus ranging from 1.5 to $3.5 \mathrm{~mm}$. Orbital floor and medial wall fractures of all patients were successfully repaired with two separated titanium mesh plates. Postoperatively, enophthalmos was improved in all patients, which was less than $2 \mathrm{~mm}$ on the last follow-up day. Hypoglobus was disappeared in all six patients postoperatively. Diplopia was resolved in five patients within 3 months post operation, and was reduced in one patient.

Conclusions: In cases of unilateral concomitant orbital floor and medial wall fractures, two titanium mesh plates implantation is a safe and effective procedure. It is worthwhile to take the technique into account when the key points to consider when applying this method include reconstruction of the special orbital shape and the complete return reposition of prolapsed intraorbital soft tissues were intended.

Keywords: Concomitant orbital fracture; transcaruncular approach; inferior subciliary approach; titanium mesh plate

Submitted Dec 02, 2020. Accepted for publication Mar 20, 2021.

doi: $10.21037 / \mathrm{atm}-21-598$

View this article at: http://dx.doi.org/10.21037/atm-21-598

^ ORCID: 0000-0002-7651-840X. 


\section{Introduction}

Orbital blowout fractures occur frequently as a result of facial trauma. Although the most common types of orbital wall fractures have orbital medial wall and orbital floor involved, the combined orbital floor and medial wall fracture have been sharply raised by now $(1,2)$. The consequences of combined orbital floor and medial wall fractures are dramatic, which contain enophthalmos, diplopia owing to ocular motility limitation, dislocation of the eyeball and the paresthesia in the area dominated by the infraorbital nerve (3). Hence, surgical intervention is generally called for repairing the orbital floor and medial wall fracture, reconstructing the complex three-dimensional shape of the orbital cavity, and repositing the intraorbital soft tissue that herniated into the paranasal sinus back into the orbit completely. Despite the advanced development of various implant materials and improvements in surgical techniques in recent years, it still remains a technical challenge for orbital surgeons in consideration of the complexity of the surgical procedures (4-6). There are multiple options of typical materials for bone wall defect repair including bone sheet, high density porous polyethylene, titanium mesh, absorbable polymer, bioactive ceramics and tissue engineering bone (7). Titanium mesh, a permanent implant, has been reported to have advantages over the other implants in repairing the large defect of orbital fracture, on account of its excellent structural support, shorter operative time, and ease of moulding into the desired shape (8). In addition, several studies focused on the surgical techniques listed following: repairment of the medial wall combined with orbital floor fractures basing on transconjunctival retro/transcaruncular approach with prebent titanium meshes implanted, to correctly accurate access to the entire medial wall and orbital floor with the inferior oblique muscle either disinserted from the bone posteriorly the inferomedial rim or divided with Stevens scissor to create "a panoramic corridor" $(9,10)$. In this study, We devised an orbital reconstruction for combined orbital floor and medial wall fracture. Two titanium mesh plates (Biomet Microfixation, Inc. 1520 Tradeport Drive Jacksonville, FL 32218, USA) were inserted via the transcaruncular and inferior subciliary approach, while the inferior oblique muscle with need not to be disinserted from the bone, and then the corner between the orbital floor and medial wall was reconstructed according to the principle of bilateral orbital symmetry. This surgical procedure was performed on 21 patients suffered combined orbital floor and medial wall fractures. The aim of this study was to evaluate the safety, reliability, and accuracy of this surgical technique, and discuss its efficacy. We present the following article in accordance with the STROBE reporting checklist (available at http://dx.doi.org/10.21037/atm-21-598).

\section{Methods}

\section{Study design}

In this study, 21 patients diagnosed as unilateral combined orbital floor and medial wall fractures at the Department of Ophthalmology, Tianjin Medical University General Hospital were enrolled from November 2010 and January 2016. Patients suffered other types of fractures were excluded when they conformed to any of the following criteria: orbital rim fracture, bilateral orbital fracture, and any history of facial fractures or diseases that could deform the orbital volume. The surgical indications for orbital wall fractures were impairment of extraocular movement and enophthalmos $\geq 3 \mathrm{~mm}$. The procedures followed were in accordance with the ethical standards of the Institute Review Board of Tianjin Medical University General Hospital and Helsinki Declaration (as revised in 2013). The Institutional Review Board of Tianjin Medical University General Hospital approved this study (No. IRB2019WZ-054). Written informed consents were obtained from all patients. Data collected for each patient included demographic characteristics, cause of injury, interval time from injury to surgery.

\section{Preoperative evaluation}

Before the operation, photographs were taken (Figure 1) and orbital computed tomography (CT) scans were obtained, including axial, coronal, and sagittal scans, as well as a three-dimensional reconstruction. A diagnosis of unilateral combined orbital floor and medial wall fracture was established according to the CT results (Figure $2 A, B$ ). All patients were examined by the same ophthalmologist for best-corrected visual acuity, diplopia, enophthalmos, and hypoglobus with detailed medical history recorded. The degree of enophthalmos was evaluated via Hertel exophthalmometer 1 day before surgery. All patients presented with enophthalmos ranging from $3.5 \mathrm{~mm}$ to $6.5 \mathrm{~mm}$. Five patients presented with diplopia with ocular motility limitation in the injured eyes, and six patients presented with hypoglobus ranging from 1.5 to $3.5 \mathrm{~mm}$ 


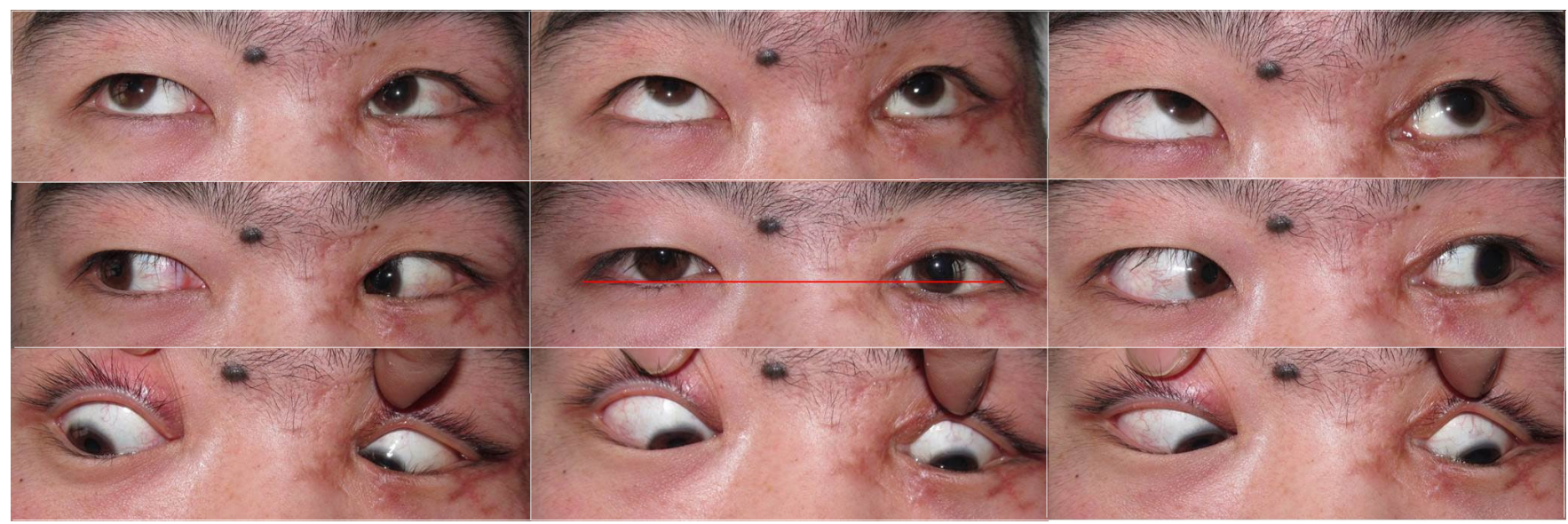

Figure 1 On preoperative examination, severe enophthalmos was observed in the left eye (4.5 mm on Hertel's exophthalmometry), and hypoglobus was also seen in the left eye ( $2.0 \mathrm{~mm}$ measured using the Bi Xiaoping method). Red line represents the normal eye position in horizontal direction as reference for correction.
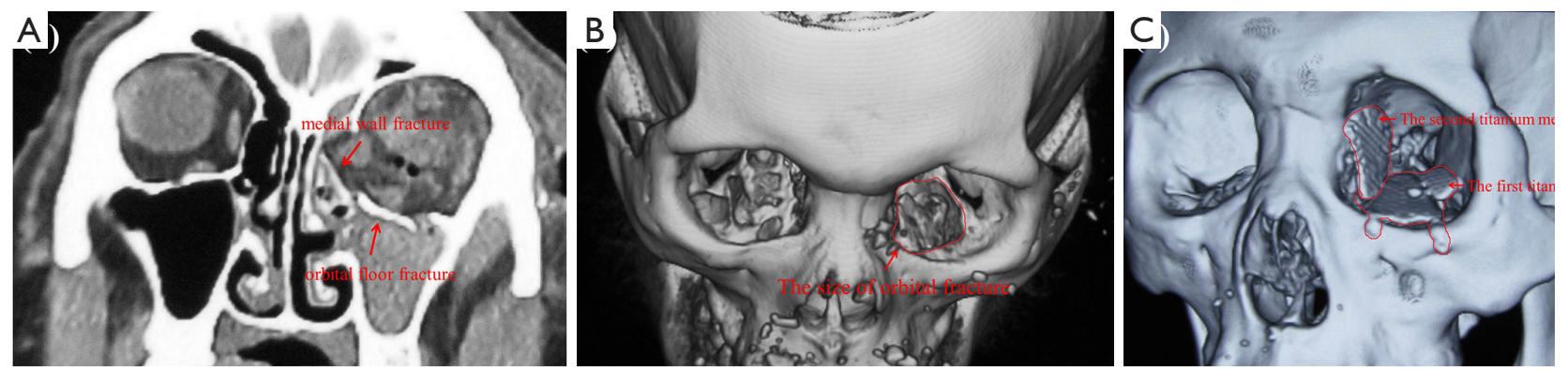

Figure 2 CT scan. (A) Preoperative coronal CT scan. Combined medial and inferior orbital fracture marked as red arrows was diagnosed in the left orbit, the orbital volume was enlarged, and intraorbital soft tissues had herniated into the paranasal sinus. (B) Preoperative threedimensional CT reconstruction showing the large defect of the fracture delineated with red line. (C) Postoperative three-dimensional CT reconstruction showing the position of the two titanium mesh plates outlined by the red line in the orbit, and reconstruction of the new corner at the transition zone area between the orbital floor and the medial wall.

(measured according to Bi Xiaoping's method) (11).

\section{Surgical procedure}

The transcaruncular approach and inferior subciliary incision with lateral canthotomy were performed in all patients under general anesthesia. Through the incisions, minimal subperiosteal dissection was carried out up to the bony rim of the orbital floor and medial wall fracture. Intraorbital soft tissues that had herniated into the paranasal sinuses were returned to the orbital cavity. The length and width of the defect of the orbital floor fracture were measured intraoperatively, and the first titanium mesh plate was shaved and shaped referred to the contralateral orbit. The medial side of the titanium mesh plate was bent with the angle being equal to that formed between the orbital floor and the medial wall of the contralateral orbit. The shaped titanium mesh plate was implanted under the periosteum and overlay the defect of the orbital floor fracture. And the implant was fixed to the inferior orbital rim with two titanium screws, which was in the symmetrical position to that of contralateral orbital floor. The second shaped titanium mesh plate was implanted under the periosteum to overlay the defect of the medial wall fracture via the transcaruncular approach. Subsequently, its inferior side was connected to the medial side of the premier titanium mesh plate in order to reconstruct the corner between the orbital floor and medial wall (Figure 2C). A forced duction test was performed immediately, and passive free eye movements 
were confirmed prior to closure of the surgical incision. The incision was closed followed by a fixation of pressure bandage in the operated orbit for 48 hours.

\section{Statistical analysis}

Descriptive data were presented in the results with no specific statistics applied.

\section{Results}

\section{Clinical features}

In this study, 21 patients (16 males and five females; age, 21-63 years; mean age, 37.6 years) with unilateral combined orbital floor and medial wall fractures underwent orbital restoration surgery using two titanium mesh plates. The most common cause of injury was traffic accident (including car and electric bicycle) in 7 cases, followed by blunt injury (e.g., sticks, fists) in 6 patients, falling from heights in 3 patients, occupational injury in 3 patients, and fireworks blast in 2 patients. The average surgical timing was 24.2 days after the injury (range, 9-63 days). All of the surgeries were uneventful. The average follow-up time was 10.6 months (range, $7-15$ months). None of patients suffered postoperative complications associated with implantation of the titanium mesh plate, such as intraorbital hematoma, infection, loss of vision, extrusion of the titanium mesh plate, or ocular motility limitation. Patient demographics are summarized in Table 1.

\section{Orbital rebabilitation}

Postoperatively, enophthalmos was improved in all patients, which was less than $2 \mathrm{~mm}$ until the last followup day. Specifically, it was $0 \mathrm{~mm}$ in seven patients, $1 \mathrm{~mm}$ in nine patients, $1.5 \mathrm{~mm}$ in three patients, and $2 \mathrm{~mm}$ in two patients. Hypoglobus was disappeared in all six patients postoperatively (Figure 3). Diplopia was resolved in five patients within 3 months postoperatively. No vision loss or decline occurred in any patients post operation. Mild retraction of the lower eyelid was seen in one patient 3 weeks post operation, which was recovered 6months later with gentle upward massage of the lower eyelid.

\section{Orbital reconstruction shown on CT scans}

Coronal CT scans and three-dimensional reconstructions were performed for all patients postoperatively, which demonstrated the appropriate location of the intraorbital soft tissues and titanium mesh plates. The titanium mesh plates were symmetrical to the contralateral orbital floor and medial wall, respectively (Figure 4).

\section{Discussion}

Orbits are symmetrical bone structures whose specific three-dimensional shape and size are critical in maintaining the shape and position of intraorbital soft tissues, as well as maintaining the normal protrusion of the eyeball (12). The occurrence of orbital blowout fractures with orbital floor and medial wall involved can result in enlargement of the orbital cavity and herniation of the orbital contents to the paranasal sinus. In addition, the contraction of retrobulbar scarringoften results in obvious enophthalmos, which causes abnormal appearance of the patient (13). Dysmotility and globe displacement can lead to diplopia at different gaze directions. Moreover, posttraumatic dysmotility may also result from direct muscle damage or edema, nerve damage, and muscle entrapment (14). Therefore, the keys to correct enophthalmos and diplopia arising from orbital floor and medial wall fractures are the precise repairment of the orbital wall defects, appropriate restoration of the anatomical shape of the orbit, and complete reposition of the prolapsed orbital contents $(15,16)$.

Theoretically, the methods and timing of operation, as well as the choice of implant, are crucial to orbital fracture prognosis equally. In general, there are two options for reconstructing orbital floor and medial wall fractures: (I) one incision, such as subcillary or inferior conjunctival fornix incisions; (II) combined incisions including one of the incisions mentioned above combined with a lateral nasal skin incision or a transcaruncular conjunctival incision. Although the basic principle for the surgical incision selection is a distinct exposure of surgical field, the surgeon may choose a discreet surgical incision in consideration of the postoperative scar formation. The inferior subcillary or fornix conjunctival incisions can expose the orbital floor and the inferior part of the medial wall rather than the superior side of the medial wall cannot be exposed (17). In our study, due to fractures with the orbital floor and medial wall involved, we selected combined incisions, i.e., a transcaruncular approach and inferior subcillary approaches with lateral canthotomy, which was demonstrated a decent approach for good surgical field exposure, and successful implantation of the titanium mesh plates without 


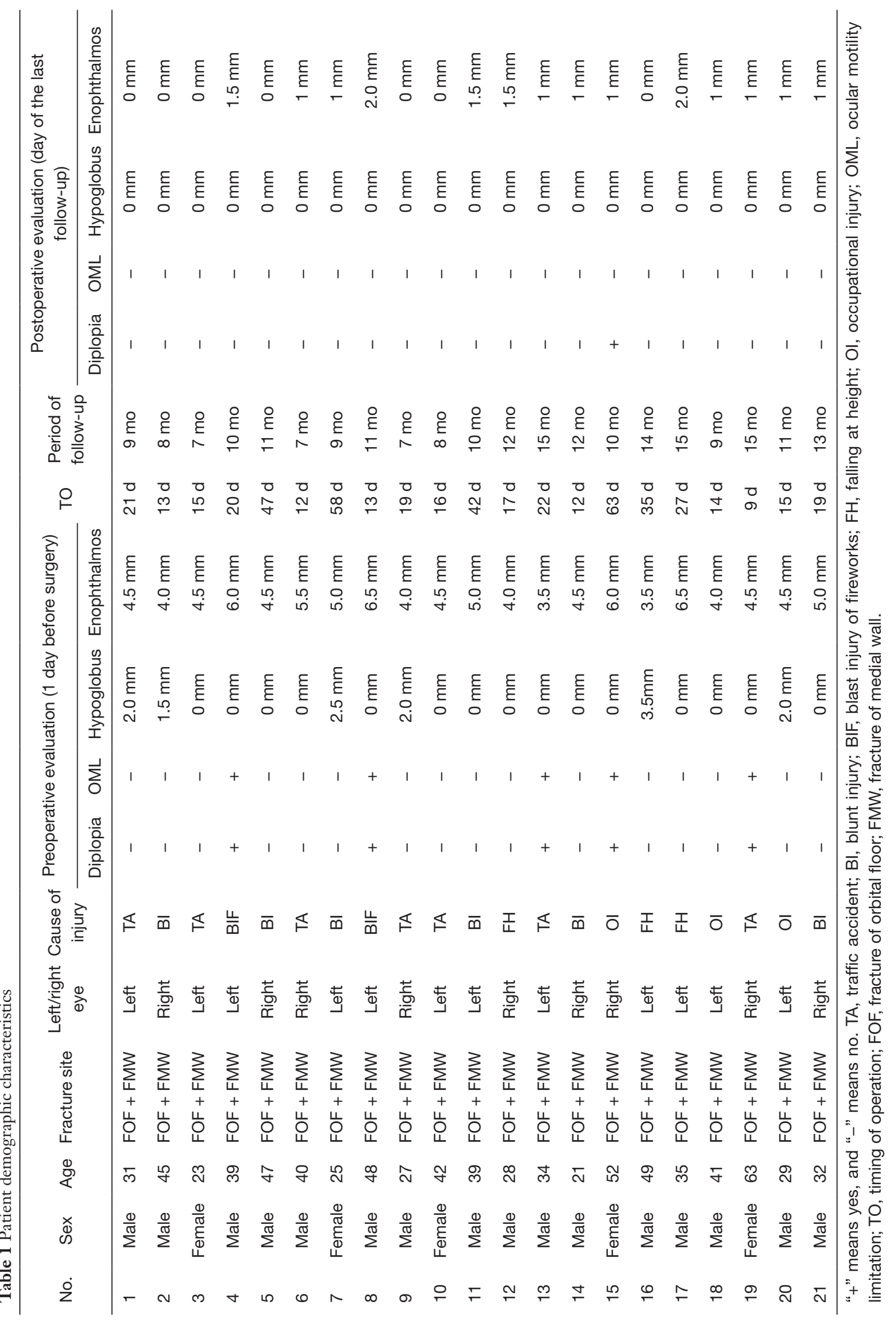




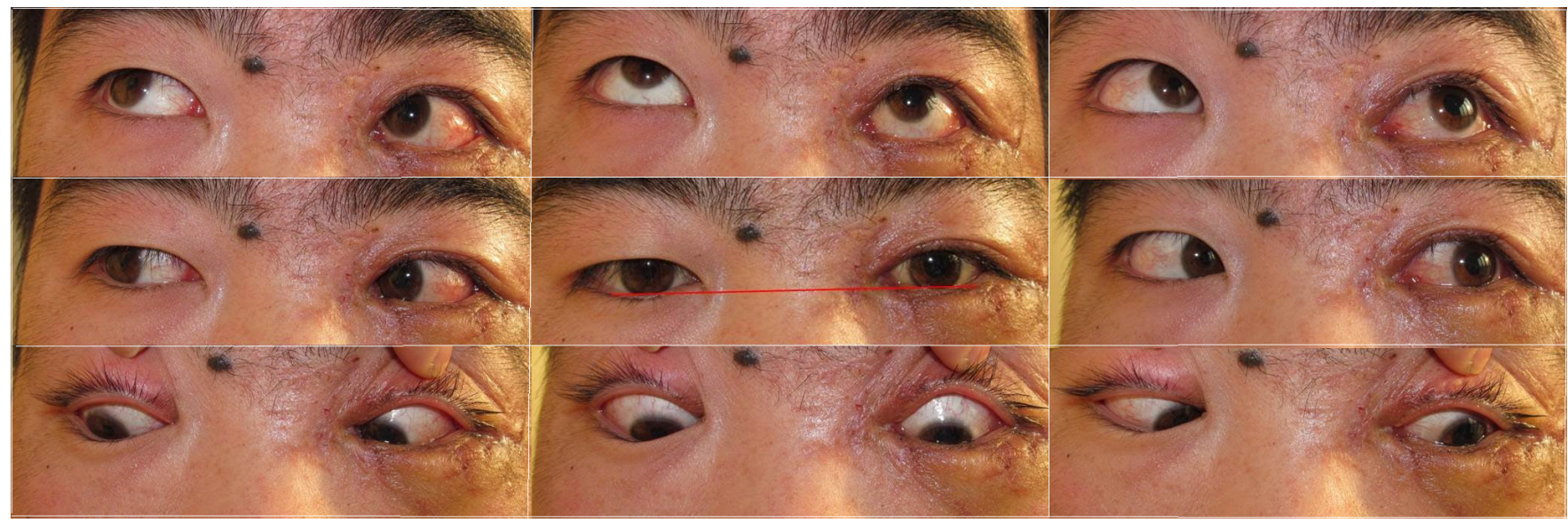

Figure 3 In the 9-month postoperative follow-up, the enophthalmos and hypoglobus were completely resolved. Red line represents the normal eye position in horizontal direction as reference for correction.

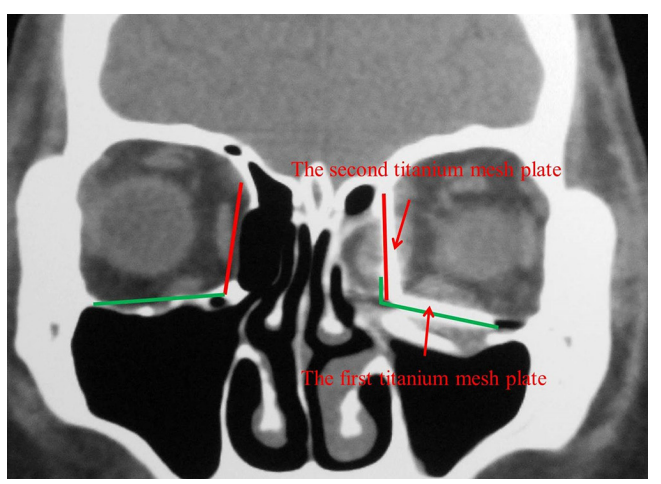

Figure 4 Postoperative coronal CT scan showing that the two titanium mesh plates were positioned well, and the "new" orbital floor and medial wall were symmetrical to that of the contralateral orbit. The red line represents the direction of the medial wall of orbit, while the green line represents that of the inferior orbital wall. The upper red arrow points out the position of the second titanium mesh plate in red line, and the lower red arrow points out the first one in green line.

intraoperative complications.

The time of surgery has been a controversial issue for decades. Some studies have shown that surgery should be required within 48 hours of the onset of trauma, since the rate of recover from diplopia was lower with increased interval before surgical intervention (18). However, other studies have reported that there were no significant difference in postoperative primary gaze diplopia between early (within 2 weeks) and delayed (after 2 weeks) repairment (19). In our perspective, the timing of surgery should be based on the patient's symptoms, clinical findings, and informed consent about the risks and benefit of surgery. Generally, it should be performed immediately in patients with ocular motility limitation and diplopia due to the entrapment of extraocular muscles confirmed by orbital CT scan. Otherwise, the surgery should be performed approximately 2 weeks after the onset of trauma $(20,21)$, when traumatic edema and hematoma have basically disappeared and tissue adhesion haven't significantly formed yet. Thus, it is easy to separate and reposit those intraorbital soft tissues that herniate into the paranasal sinus, and the surgical outcome is better than that performed immediately after trauma. Additionally, tissue adhesion and scar contraction at large stage might increase difficulty of delayed surgery $(22,23)$. In our study, the average of surgical timing was 24.2 days after trauma (range, 9-63 days), which was postponed due to delayed consultation in our clinic. Intraoperatively, there were fibrous scar and tissue adhesion between the rim of the orbital fracture and the herniated intraorbital soft tissues in some patients. A careful manipulation underneath the periosteum should be applied to avoid damaging the normal intraorbital soft tissue.

Various implant materials have been used for orbital fracture repairs, such as autologous bone grafts $(24,25)$, porous polyethylene $(26,27)$, polydioxanone $(28,29)$, bioresorbable polylactide plates $(30,31)$, silicone $(32,33)$, smooth nylon foil $(34,35)$, and titanium mesh $(36,37)$. However, it is still controversial to figure out the ideal implant materials and methods for orbital floor and medial wall fracture repairment (38). By now, two options have been proposed to determine the implant materials: (I) one 
kind of implant material; and (II) two kinds of implant materials, such as a combination of a titanium mesh plate and aPorous high-density polyethylene (Medpor) implant, in which titanium mesh would be used to repair the orbital wall fracture and Medpor decrease the orbital volume. The second opinion has been shown be beneficial to enophthalmos correction (39). Under certain circumstance, repairment with multilayer implants is an option for severe enophthalmos correction. However, displacement of the eyeball could occur when the anterior orbital floor fracture was repaired (40). There are also two options for surgical method: (I) implantation of two separated implants to repair the orbital floor and medial wall fracture, respectively; (II) implantation of one implant to repair the orbital floor and medial wall fracture simultaneously. For the second method, the prolapsed orbital soft tissues could easily entrap intraorbital soft tissues or damage important orbital structures in the course of the forceful insertion of the implant (41).

For the sake of reconstruction of the same special threedimensional orbital shape as the contralateral orbit and decrease of the difficulty and risks of surgery, two separated titanium mesh plates were implanted through two surgical incisions and were connected tightly at the corner of the orbital floor and medial wall. The "new" orbital floor and medial wall were formed symmetrical to that of contralateral orbit shown on postoperative CT scans, meanwhile, the enophthalmos was significantly improved. All patients initially presented with enophthalmos ranging from 3.5 to $6.5 \mathrm{~mm}$, which had been improved to less than $2 \mathrm{~mm}$ on the last follow-up day. Specifically, enophthalmos was $0 \mathrm{~mm}$ in seven patients, $1 \mathrm{~mm}$ in nine patients, $1.5 \mathrm{~mm}$ in three patients, and $2 \mathrm{~mm}$ in two patients. The intraoperative bend of titanium mesh plate provided high contour accuracy and ease of application in the repair of the unilateral orbital floor and medial wall fracture compared to the patient-specific, time-consuming, and costly stereolithographic (STL) implant (42). Additionally, there were no postoperative complications associated with the titanium mesh plate, such as infection, extrusion of the implant, decreased or loss of vision, or ocular motility limitation. These results demonstrate that the titanium mesh plate is a safe material and the technique we used is applied to the repairment of orbital floor and medial wall fractures.

On behalf of reconstructing the orbital cavity and correcting enophthalmos arising from orbital floor and medial wall fractures, it is necessary to locate an anatomic landmark to repair the fracture, restore the normal orbital volume, and especially reconstruct the posterior orbital cavity (43). In our study, this problem was successfully resolved by using the symmetrical principle of bilateral orbits. The first titanium mesh plate was implanted and fixed, ensuring that the position of the corner, which was shaped at the medial side of plate, was symmetrical to that formed between the contralateral orbital floor and the medial wall. The second plate was then implanted with its inferior side connected tightly to the medial side of the first plate to reconstruct the corner. In this way, we could decrease the enlarged orbital volume caused by orbital fracture, correct the enophthalmos and hypoglobus, and improve the appearance of patients. The difficulty associated with this technique are how to properly repair the orbital floor and medial wall fracture, and how to decide the right position of the corner formed between these two orbital walls. In addition, the intraorbital soft tissues that herniate into the paranasal sinus should be separated completely and repositioned regularly, which is beneficial for correcting enophthalmos, eliminating diplopia, and improving the appearance of patients.

In summary, we believe that the application of two titanium mesh plates in repairing unilateral orbital floor and medial wall fractures and correcting enophthalmos offers the following advantages: (I) reconstruction of the special orbital shape and normal volume; and (II) reduced difficulty of surgery and risk of complications. It is safe and effective for the application of two titanium mesh plates is safe and effective in repairing unilateral orbital floor and medial wall fractures, though the small sample size might not be sufficient to draw generalized conclusions and require further studies. But it is worthwhile to take the technique into account when reconstruction of the special orbital shape and the complete reposition of prolapsed intraorbital soft tissues were intended.

\section{Acknowledgments}

Funding: This article was financed by the National Natural Science Foundation of China (Grant Numbers 81830026), the Natural Science Foundation of Tianjin (Grant Number 18ZXDBSY00030), and the Natural Science Foundation of Tianjin (Beijing-Tianjin-Hebei Special Program: Grant Number 19JCZDJC64300).

\section{Footnote}

Reporting Checklist: The authors have completed the 
Narrative Review reporting checklist. Available at http:// dx.doi.org/10.21037/atm-21-598

Data Sharing Statement: Available at http://dx.doi. org/10.21037/atm-21-598

Conflicts of Interest: All authors have completed the ICMJE uniform disclosure form (available at http://dx.doi. org/10.21037/atm-21-598). The authors have no conflicts of interest to declare.

Ethical Statement: The authors are accountable for all aspects of the work in ensuring that questions related to the accuracy or integrity of any part of the work are appropriately investigated and resolved. The procedures followed were in accordance with the ethical standards of the Institute Review Board of Tianjin Medical University General Hospital and Helsinki Declaration (as revised in 2013). The Institutional Review Board of Tianjin Medical University General Hospital approved this study (No. IRB2019-WZ-054). Written informed consents were obtained from all patients.

Open Access Statement: This is an Open Access article distributed in accordance with the Creative Commons Attribution-NonCommercial-NoDerivs 4.0 International License (CC BY-NC-ND 4.0), which permits the noncommercial replication and distribution of the article with the strict proviso that no changes or edits are made and the original work is properly cited (including links to both the formal publication through the relevant DOI and the license). See: https://creativecommons.org/licenses/by-nc-nd/4.0/.

\section{References}

1. Chi MJ, Ku M, Shin KH, et al. An analysis of 733 surgically treated blowout fractures. Ophthalmologica 2010;224:167-75.

2. Çağatay HH, Ekinci M, Pamukcu C, et al. Retrospective analysis of 132 patients with orbital fracture. Ulus Travma Acil Cerrahi Derg 2013;19:449-55.

3. Marano R, Tincani AJ. Is there an ideal implant for orbital reconstructions? Prospective 64-case study. J Craniomaxillofac Surg 2016;44:1682-8.

4. Rosado P, de Vicente JC. Retrospective analysis of 314 orbital fractures. Oral Surg Oral Med Oral Pathol Oral Radiol 2012;113:168-71.

5. He Y, Zhang Y, An JG. Correlation of types of orbital fracture and occurrence of enophthalmos. J Craniofac Surg 2012;23:1050-3.

6. Lim NK, Kang DH, Oh SA, et al. Orbital wall restoring surgery in pure blowout fractures. Arch Plast Surg 2014;41:686-92.

7. Yu J, Xu Q, Wang Y, et al. Advances in the research and application of orbital blowout fracture repair material. Zhonghua Yan Ke Za Zhi 2019;55:876-80.

8. González Magaña F, Menéndez Arzac R, De Hilario Avilés L. Combined use of titanium mesh and resorbable PLLA-PGA implant in the treatment of large orbital floor fractures. J Craniofac Surg 2011;22:1991-5.

9. Woo KS, Cho PD, Lee SH. Reconstruction of severe medial orbital wall fractures using titanium mesh plates by the pericaruncular approach. J Plast Surg Hand Surg 2014;48:248-3.

10. Gerbino G, Zavattero E, Viterbo S, et al. Treatment of orbital medial wall fractures with titanium mesh plates using retrocaruncular approach: outcomes with different techniques. Craniomaxillofac Trauma Reconstr 2015;8:326-3.

11. Bi XP, Pan XQ, Shi WD, et al. Three-dimensionally preformed titanium mesh paltes for posttraumatic complex orbital bone fracture reconstruction. Zhonghua Yan Ke Za Zhi 2011;47:683-7.

12. Ramieri G, Spada MC, Bianchi SD, et al. Dimensions and volumes of the orbit and orbital fat in posttraumatic enophthalmos. Dentomaxillofac Radiol 2000;29:302-11.

13. Longaker MT, Kawamoto HK. Enophthalmos revisited. Clin Plast Surg 1997;24:531-7.

14. Grob S, Yonkers M, Tao J. Orbital Fracture Repair. Semin Plast Surg 2017;31:31-9.

15. Chen CT, Chen YR. Update on orbital reconstruction. Curr Opin Otolaryngol Head Neck Surg 2010;18:311-6.

16. Lee KM, Park JU, Kwon ST, et al. Three-dimensional pre-bent titanium implant for concomitant orbital floor and medial wall fractures in an East asian population. Arch Plast Surg 2014;41:480-5.

17. Chen ZY, Liu JM, Song WX, et al. Surgical repair of medial orbital wall combined with orbital floor fracture via lower lid subciliary approach. Ophthalmol CHN 2006;15:369-72.

18. Kim NH, Kang SJ. Correlation between the time to surgery and that to recovery from postoperative diplopia based on a single-center, retrospective experience: a case series of 11patients. Arch Plast Surg 2014;41:486-92.

19. Ceylan OM, Uysal Y, Mutlu FM, et al. Management of diplopia in patients with blowout fractures. Indian J 
Ophthalmol 2011;59:461-4.

20. Sugamata A, Yoshizawa N, Shimanaka K. Timing of operation for blowout fractures with extraocular muscle entrapment. J Plast Surg Hand Surg 2013;47:454-7.

21. Gonzalez MO, Durairaj VD. Indirect Orbital Floor Fractures: A Meta-Analysis. Middle East Afr J Ophthalmol 2010;17:138-41.

22. Poeschl PW, Baumann A, Dorner G, et al. Functional outcome after surgical treatment of orbital floor fractures. Clin Oral Investig 2012;16:1297-303.

23. Tan Başer N, Bulutoğlu R, Çelebi NU, et al. Clinical management and reconstruction of isolated orbital floor fractures: The role of computed tomography during preoperative evaluation. Ulus Travma Acil Cerrahi Derg 2011;17:545-53.

24. Pereira Rdos S, Jorge-Boos FB, Hochuli-Vieira E, et al. Management of pure medial orbital wall fracture with autogenous bone graft. J Craniofac Surg 2013;24:e475-7.

25. Zunz E, Blanc O, Leibovitch I. Traumatic orbital floor fractures: repair with autogenous bone grafts in a tertiary trauma center. J Oral Maxillofac Surg 2012;70:584-92.

26. Chou C, Kuo YR, Chen CC, et al. Medial Orbital Wall Reconstruction With Porous Polyethylene by Using a Transconjunctival Approach With a Caruncular Extension. Ann Plast Surg 2017;78:S89-94.

27. Colletti G, Saibene AM, Giannini L, et al. Endoscopic endonasal repair with polyethylene implants in medial orbital wall fractures: A prospective study on 25 cases. J Craniomaxillofac Surg 2018;46:274-82.

28. Beck-Broichsitter BE, Acar C, Kandzia C, et al. Reconstruction of the orbital floor with polydioxanone: a long-term clinical survey of up to 12 years. Br J Oral Maxillofac Surg 2015;53:736-40.

29. Gierloff M, Seeck NG, Springer I, et al. Orbital floor reconstruction with resorbable polydioxanone implants. J Craniofac Surg 2012;23:161-4.

30. Lieger O, Schaller B, Zix J, et al. Repair of orbital floor fractures using bioresorbable poly-L/DL-lactide plates. Arch Facial Plast Surg 2010;12:399-404.

31. Al-Sukhun J, Törnwall J, Lindqvist C, et al. Bioresorbable poly-L/DL-lactide (P(L/DL)LA 70/30) plates are reliable for repairing large inferior orbital wall bony defects: a pilot study. J Oral Maxillofac Surg 2006;64:47-55.

32. Shim HS, Lim SY, Lim JS. A simple and easy surgical technique for open reduction of orbital wall fractures using a silicone sheet. J Plast Reconstr Aesthet Surg 2014;67:e308-9.

33. Reilly BK, Sidle DM. Correction of delayed enophthalmos using a custom-fashioned silicone sheeting implant. Ear Nose Throat J 2010;89:586-8.

34. Park DJ, Garibaldi DC, Iliff NT, et al. Smooth nylon foil (SupraFOIL) orbital implants in orbital fractures: a case series of 181 patients. Ophthalmic Plast Reconstr Surg 2008;24:266-70.

35. Majmundar MV, Hamilton JS. Repair of orbital floor fractures with SupraFOIL Smooth Nylon Foil. Arch Facial Plast Surg 2007;9:64-5.

36. Chen CH, Chen CT, Wang PF, et al. A novel anatomical thin titanium mesh plate with patient-matched bending technique for orbital floor reconstruction. J Craniomaxillofac Surg 2018;46:1526-32.

37. Brucoli M, Boccafoschi F, Boffano P, et al. The Anatomage Table and the placement of titanium mesh for the management of orbital floor fractures. Oral Surg Oral Med Oral Pathol Oral Radiol 2018;126:317-21.

38. Bratton EM, Durairaj VD. Orbital implants for fracture repair. Curr Opin Ophthalmol 2011;22:400-6.

39. Jiang QY, Guo T, Sha YH, et al. Titanium mesh combined with Medpor implantation in orbital reconstruction for medial and inferior. Chin J Ocul Traum Occupat Eye Dis 2012;34:885-7.

40. Xiao LX, Wang Y. Pre-bent titanium implant for orbital blowout fracture. Chin J Ophthalmol 2013;49:762-4.

41. Xiao LH, Wang Y, Yang XJ, et al. En-bloc repairing for blow-out fractures of orbital medial and inferior walls in 29 cases. Ophthalmol CHN 2006;15:348-50.

42. Strong EB, Fuller SC, Wiley DF, et al. Preformed vs intraoperative bending of titanium mesh for orbital reconstruction. Otolaryngol Head Neck Surg 2013;149:60-6.

43. Wang SG, Zou JX, Zhang FY, et al. Postoperative enophthalmos in inner and inferior orbital fracture repaired by titanium mesh. Chin J Ocul Traum Occupat Eye Dis 2013;35:434-5.

(English Language Editor: A. Kassem)

Cite this article as: Yu J, Zhang J, Chen S, Han Q, Yan H. Repair of unilateral combined orbital floor and medial wall fracture using two titanium mesh plates: a modified technique. Ann Transl Med 2021;9(6):463. doi: 10.21037/atm-21-598 